\title{
Surface Roughness Changes by Finescale Current Gradients: Properties at Multiple Azimuth View Angles ${ }^{\mathfrak{O}}$
}

\author{
NICOLAS RASCLE \\ Laboratoire d'Océanographie Spatiale, Institut Francais de Recherche pour l'Exploitation de la Mer, \\ Plouzané, France \\ FREDERIC NOUGUIER \\ Université de Toulon, CNRS/INSU, IRD, Mediterranean Institute of Oceanography, UM 110, \\ La Garde, France \\ Bertrand Chapron, Alexis Mouche, and Aurélien Ponte \\ Laboratoire de Physique des Océans, Institut Francais de Recherche pour l'Exploitation \\ de la Mer, Plouzané, France
}

(Manuscript received 29 July 2015, in final form 26 September 2016)

\begin{abstract}
At times, high-resolution images of sea surface roughness can provide stunning details of submesoscale upper-ocean dynamics. As interpreted, transformations of short-scale wind waves by horizontal current gradients are responsible for those spectacular observations. Those observations could prove particularly useful to validate numerical ocean models that reach increasingly high resolutions. Focusing on surface roughness at optical wavelengths, two steps have recently been performed in that direction. First, it was shown in a previous paper by Rascle et al. that surface roughness variations not only trace surface current divergence but also other characteristics of the current gradient tensor, mainly the strain in the wind direction. The wind direction with respect to the current gradient thus stands out as an important interpretative parameter. The second step is the purpose of the present paper, where the effect of the viewing direction is investigated. To this end, the authors discuss pairs of quasi-simultaneous sun-glitter images, taken from different satellite positions, to provide different viewing configurations, namely, quasi-orthogonal azimuth angles at similar zenith angles. As evidenced, upwind and crosswind viewing observations can be markedly different. As further confirmed with idealized numerical simulations, this anisotropy well traces anisotropic surface current areas, while more isotropic contrasts likely trace areas dominated by surface divergence conditions. These findings suggest the potential to directly separate divergence from other deformations by using highresolution roughness observations at multiple azimuth view angles.
\end{abstract}

\section{Introduction}

Fluctuations of the upper ocean at horizontal scales lower than $30 \mathrm{~km}$ include internal waves and submesoscale fronts and filaments whose role for vertical exchanges with the ocean interior and for the dispersion of horizontal tracers has been highlighted by both

Supplemental information related to this paper is available at the Journals Online website: http://dx.doi.org/10.1175/JPOD-15-0141.s1.

Corresponding author e-mail: Nicolas Rascle, nicolas.rascle@ ifremer.fr theoretical and high-resolution numerical modeling studies (Spall 1995; Nagai et al. 2006; Thomas et al. 2008; Klein and Lapeyre 2009; Zhong and Bracco 2013; Callies et al. 2015; Brannigan et al. 2015). Consequently, proper understanding of the marine biochemical and ecological functioning and of the impact of finescale vertical exchanges of heat and carbon on climatic scales hinges on our ability to observe and estimate the dynamics of these motions (Ferrari 2011; Perruche et al. 2011; Lévy et al. 2012). Ambitious field experiments have recently been undertaken to do so (Özgökmen et al. 2014; Shcherbina et al. 2015), but there is still a lack of more systematic means of observing the ocean dynamics at these scales. 
Surface roughness images might fulfill this lack, as they often capture spectacular manifestations of finescale upper-ocean dynamics, including internal waves, fronts, filaments, and spiraling eddies at scales between 1 and 30 km (e.g., Fu and Holt 1983; Alpers 1985). Those images are routinely obtained with high-resolution satellite sensors, for example, from passive optical radiometers viewing areas in and around the sun glitter and from active radar instruments (e.g., Apel et al. 1975; Beal et al. 1981; Kudryavtsev et al. 2012a).

Surface roughness in sun-glitter images is determined by specularly reflected sunlight, which is locally related to wave slope distribution. The latter is largely controlled by the directional mean square slope (mss; Cox and Munk 1954). For radar images, the backscatter intensity is less directly affected by specular reflection, and other geometrical properties of the surface (e.g., wave breaking and rms height at very short resonant scales) must be taken into account (Kudryavtsev et al. 2005). In this paper, we ignore radar roughness to focus on sunglitter observations and we assume, for simplicity, that wave slope properties are dominated by mss properties.

As interpreted, the finescale features observed on surface roughness images are due to modulations of short (wavelength $\sim 1 \mathrm{~m}$ ) wind waves by horizontal current gradients. Those modulations can be essentially related to three mechanisms: 1) The presence of surfactants, possibly accumulated in zones of surface current convergence, can damp short gravity waves (e.g., Espedal et al. 1998). 2) The modification of sea surface properties (temperature, current, or roughness) can alter the atmospheric boundary layer and thus modify the wind, which in turns modifies short waves (e.g., Beal et al. 1997). 3) Surface current gradients can directly refract or alter the short-scale wave field (e.g., Phillips 1984). Mechanism 1, because of convergence processes and surfactants (e.g., McWilliams et al. 2009), is likely limited to very low wind speed, except for isolated cases of marine pollution. Mechanism 2 involves modification of the atmospheric boundary layer that seemingly occurs at larger spatial scales than current refraction (Kudryavtsev et al. 2005). Nonetheless, the interactions at fine spatial scales between atmospheric boundary layer, sea surface temperature, surface roughness, and current are not well known and will deserve future attention. In the present paper, we focus on mechanism 3 as it is likely the principal mechanism explaining surface roughness modifications at fine spatial scales.

Based on the conservation of wave action, Phillips (1984) studied the modulation of an individual wave over a varying current, and Dulov and Kudryavtsev (1990) extended it to modulations of a complete spectrum of wind waves. Under the assumption that the wave field is symmetrical about the wind direction, Rascle et al. (2014) showed that surface roughness is mainly modulated by two characteristics of the surface current horizontal deformation, the divergence, and the strain in the wind direction. Vorticity and shear in the wind direction should have a smaller impact. The wind direction with respect to the current gradient is then an important factor to control the surface roughness modulation.

A subsequent property is to possibly separate the divergence and strain from the roughness observations. Whereas the current divergence is isotropic in the sense that it acts similarly on waves propagating in any direction, the current strain should not have the same impact on crosswind-propagating waves compared to upwind/downwind-propagating waves. In that respect, the azimuth view direction (which depends on the sun and satellite positions) stands out as another important parameter to interpret the surface roughness modulation.

In the present paper, we wish to illustrate these properties using surface roughness observations at multiple azimuth view angles. We investigate pairs of quasi-simultaneous sun-glitter observations from different satellite positions, offering different view angles, in particular quasi-orthogonal azimuth angles at similar zenith angles. Those observations show evidence of an anisotropic surface roughness response, as described in section 2. Surface roughness modulation by current can thus be considered as a vectorial (i.e., anisotropic or directional) quantity. The assumption that it is a scalar (i.e., isotropic or omnidirectional) quantity is only strictly valid for damping effects induced by surfactants. In section 3, we study wave-current interactions in a simplified relaxation framework to distinguish between divergence effects that create quasi-isotropic surface roughness modulations from current strain effects that can create anisotropic roughness modulations. As further confirmed with idealized numerical simulations, these developments provide plausible explanations of the observations (section 4). The consequences of those results are discussed in section 5. A conclusion is drawn in section 6 .

\section{Sun-glint observations}

\section{a. The radiometers}

The properties that we wish to illustrate are found in numerous examples of oceanic fronts seen by pairs of optical images around the sun-glitter area. Different examples can be found in the supplemental information. Here, we chose to extensively investigate two pairs of images of the Gulf Stream inner front. Pair 1 (Fig. 1) was acquired within a 48-min interval on 1 April 2010 by (i) the radiance band 15 (centered at $900 \mathrm{~nm}$ ) measured 
(a) MERIS Radiance Contrast B'/B

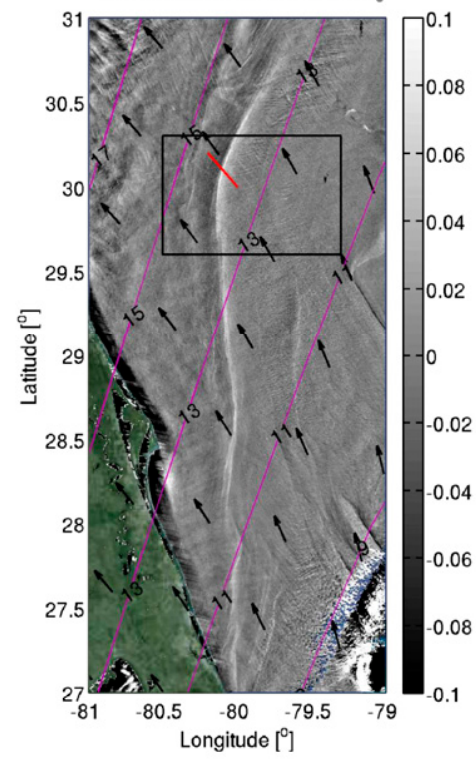

(d) MERIS Radiance Contrast 3'/8

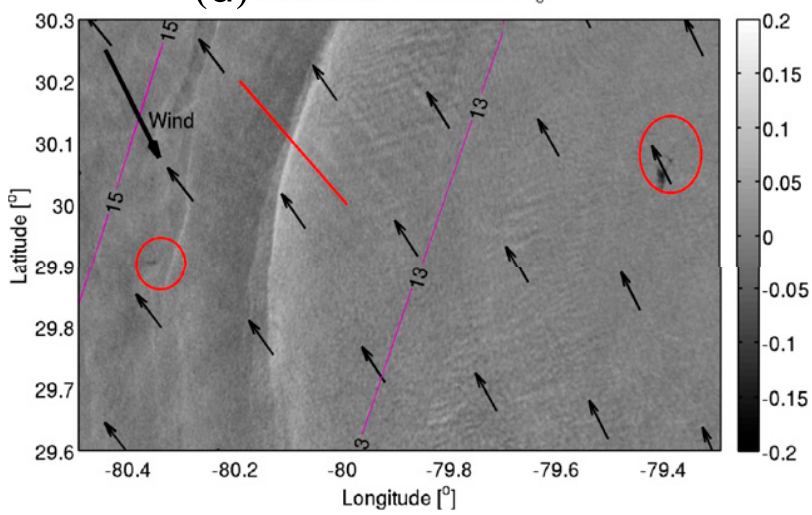

(b) MODIS Terra Radiance Contrast $B^{\prime} B_{0}$

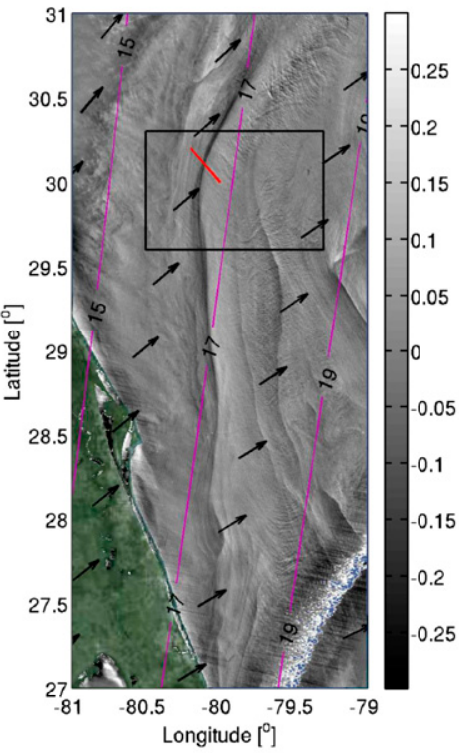

(C) MODIS Terra Brightness Temperature $\left.\mathrm{T}_{\mathrm{B}} \mathrm{I}^{\circ} \mathrm{C}\right]$

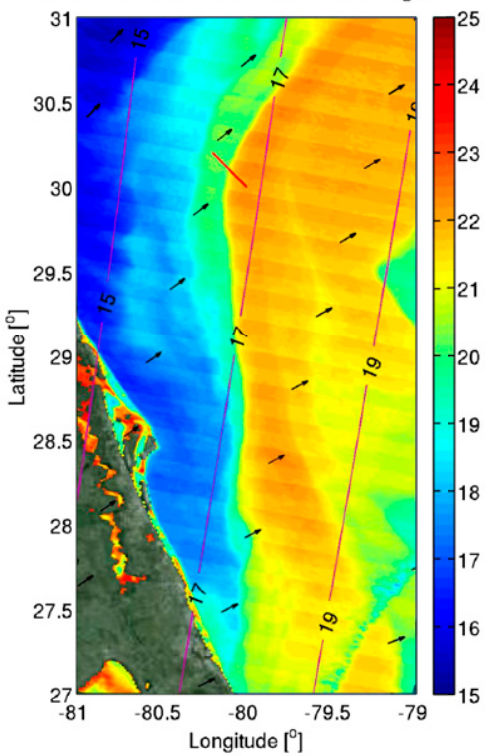

(e) MODIS Terra Radiance Contrast B'B $B_{0}$
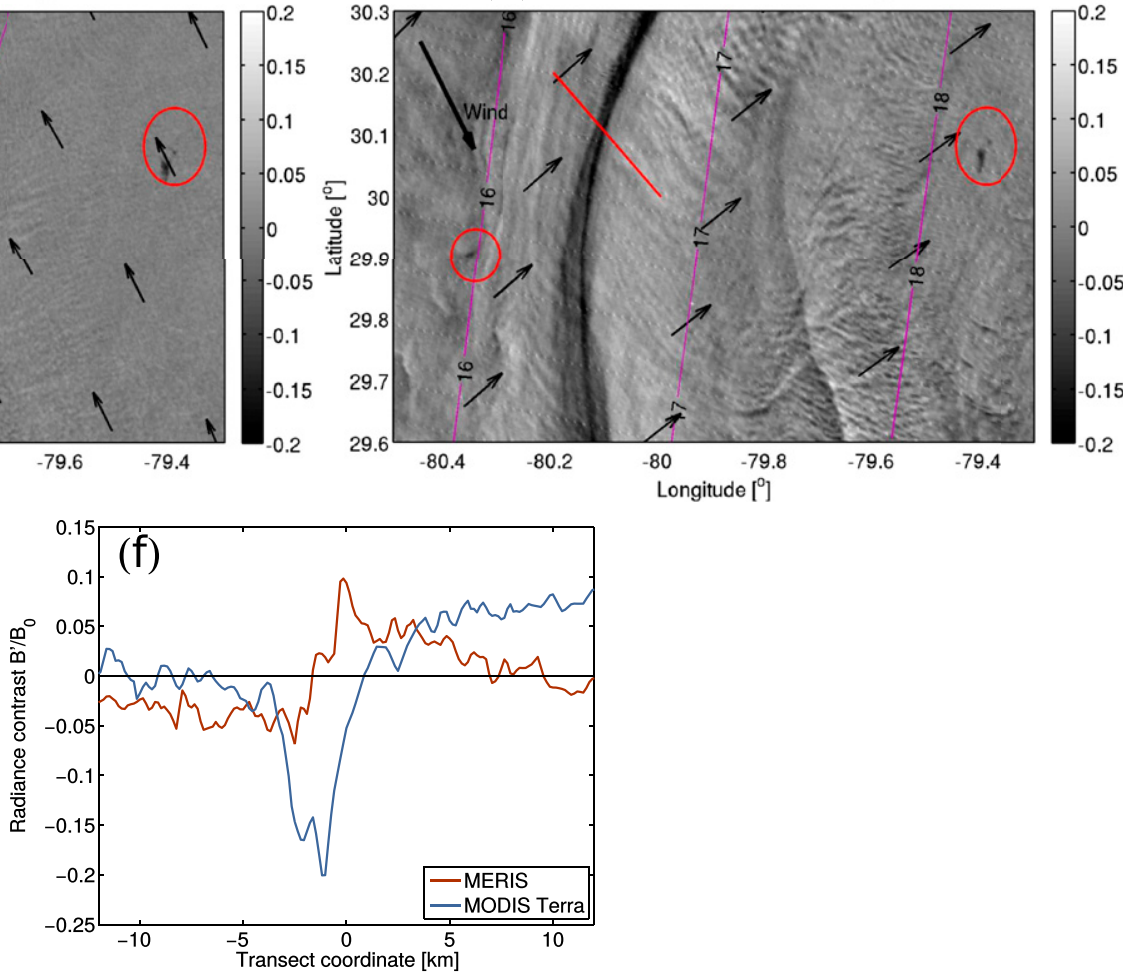

FIG. 1. Image pair 1: Radiance contrasts $B^{\prime} / B_{0}$ around the sun glitter in the Gulf Stream region on 1 Apr 2010, from (a) MERIS and (b) MODIS Terra. Contours and arrows show, respectively, the zenith $\theta_{m}$ and azimuth $\varphi_{m}$ angles of the equivalent monostatic view. (c) MODIS Terra brightness temperature. (d),(e) Zooms on the black boxes of (a) and (b). A transect in the Gulf Stream inner front is shown in red, and surface slicks nearby are circled in red. (f) Radiance contrasts $B^{\prime} / B_{0}$ along the transect shown in red.

by Medium Resolution Imaging Spectrometer (MERIS; Huot et al. 2001) on board Envisat, at 1542 UTC, and (ii) the radiance band 2 (centered at $850 \mathrm{~nm}$ ) measured by Moderate Resolution Imaging Spectroradiometer
(MODIS; Salomonson et al. 1989) on board Terra at 1630 UTC. The pair 2 (Fig. 2) was acquired within a 2-min interval on 29 June 2012 at 1606 UTC by Multiangle Imaging Spectroradiometer (MISR; Diner et al. 1989) 


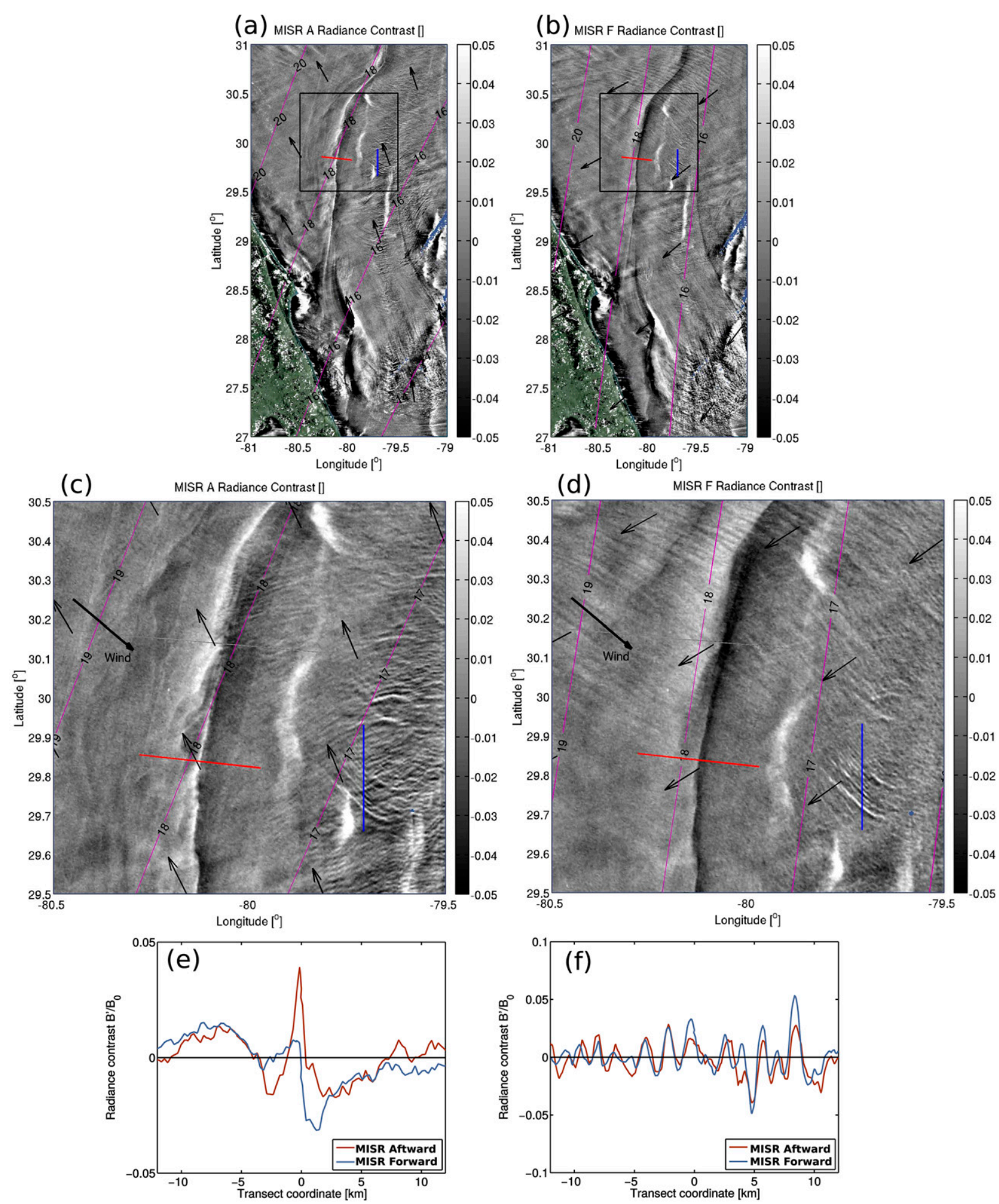

FIG. 2. Image pair 2: (a),(b) Radiance contrasts $B^{\prime} / B_{0}$ on 29 June 2012 from (a) MISR F and (b) MISR A. Contours and arrows are similar to those of Fig. 1. (c),(d) Zooms on the black boxes of (a) and (b). (e),(f) Radiance contrasts $B^{\prime} / B_{0}$ along the transects shown in red and blue, respectively, across the Gulf Stream and across a train of subsurface waves. 
on board Terra using the red radiance (centered at $670 \mathrm{~nm}$ ) measured by first forward (F) and aftward (A) cameras, which are arranged symmetrically $26.1^{\circ}$ about the nadir and, respectively, forward and aftward of the satellite local vertical.

The images have a horizontal resolution of about $250 \mathrm{~m}$. The observed radiance $B=B_{0}+B^{\prime}$ is separated into a slowly varying background $B_{0}$ and a local anomaly $B^{\prime}$ by horizontally filtering with a cutoff scale $L=25 \mathrm{~km}$, and we focus on the radiance contrast $B^{\prime} / B_{0}$.

\section{b. Ocean-meteorological conditions}

Envisat and Terra were also equipped with infrared radiometers for SST retrieval. In Fig. 1c, we show the brightness temperature $T_{B}$ calculated from the MODIS Terra channel at $11 \mu \mathrm{m}$ using the SeaWiFS operational Data Analysis System (SeaDAS) 6.0 (Fu et al. 1998). Most of the fronts seen on the roughness images correspond to surface temperature fronts. For image pair 1 on 1 April 2010, the wind was blowing from the northnorthwest (NNW; with an azimuth angle of $\varphi_{w} \simeq-30^{\circ}$ relative to the north), as evidenced by the presence of aligned wind streaks (Vandemark et al. 2001) on the MERIS image (Fig. 1a, in the region around $30.6^{\circ} \mathrm{N}$, $80.3^{\circ} \mathrm{W}$ ). Numerical meteorological reanalysis (ERAInterim; Dee et al. 2011) and nearby scatterometer measurements at 1600 UTC [ASCAT; Ocean and Sea Ice Satellite Application Facility (OSI SAF 2016)] both confirm very light winds in the area $\left(5 \mathrm{~m} \mathrm{~s}^{-1}\right.$; not shown). For image pair 2 on 29 June 2012, ASCAT measurement at 1446 UTC indicates wind about $6-8 \mathrm{~m} \mathrm{~s}^{-1}$ from the west. As evidenced from the aligned wind streaks (Fig. 2), at 1606 UTC the wind direction was from the northwest (at an angle $\varphi_{w} \simeq-50^{\circ}$ ).

\section{c. Geometry of the observations}

We consider the surface brightness field in the sunglitter area where the impact of the sky radiance reflected from the surface to the sensor is negligible. Following Cox and Munk (1954), the sun-glitter radiance $B$, generated by specular reflection of the sun light, is given as

$$
B=\frac{\rho E_{\mathrm{su}}}{4 \cos \theta_{\mathrm{se}} \cos ^{4} \theta_{m}} P\left(Z_{x}, Z_{y}\right),
$$

where $E_{\mathrm{su}}$ is the sun irradiance, $\rho$ is the Fresnel reflection coefficient, $P\left(z_{x}, z_{y}\right)$ is the $2 \mathrm{D}$ probability density function (PDF) of the eastward $z_{x}$ and northward $z_{y}$ sea surface slopes, and capital $Z_{x}$ and $Z_{y}$ denote their values satisfying the conditions of specular reflections of the sun light received by the sensor.

Sun-glitter observations operate in a bistatic configuration (see the appendix for more details). Let $\theta_{\mathrm{se}}$ and $\theta_{\text {su }}$ be the sensor and sun zenith incidence angles (measured from the vertical; see Fig. A1) and $\varphi_{\text {se }}$ and $\varphi_{\mathrm{su}}$ the sensor and sun azimuth angles (measured clockwise from the north; see Fig. A1). Then the specular eastward and northward slopes are

$$
\begin{aligned}
& Z_{x}=-\frac{\sin \theta_{\mathrm{su}} \cos \varphi_{\mathrm{su}}+\sin \theta_{\mathrm{se}} \cos \varphi_{\mathrm{se}}}{\cos \theta_{\mathrm{su}}+\cos \theta_{\mathrm{se}}}, \\
& Z_{y}=-\frac{\sin \theta_{\mathrm{su}} \sin \varphi_{\mathrm{su}}+\sin \theta_{\mathrm{se}} \sin \varphi_{\mathrm{se}}}{\cos \theta_{\mathrm{su}}+\cos \theta_{\mathrm{se}}}
\end{aligned}
$$

and we can define an equivalent monostatic look direction with

$$
\theta_{m}=\arctan \sqrt{Z_{x}^{2}+Z_{y}^{2}}, \quad \varphi_{m}=\arctan \left(Z_{y} / Z_{x}\right),
$$

the zenith and azimuth angles. Those angles correspond to a virtual situation where the satellite would be its own sun (as it is the case for active radars; see the appendix).

Those angles are shown in Figs. 1 and 2 as contours and arrows. For image pair 1, MERIS and MODIS Terra have similar zenith angles $\theta_{m} \simeq 14^{\circ}-16^{\circ}$ but quasiorthogonal azimuth angles, with MERIS looking approximately upwind and MODIS Terra looking crosswind. For image pair 2, MISR $\mathrm{A}$ and $\mathrm{F}$ have equal zenith angles $\theta_{m}=18^{\circ}$ and quasi-orthogonal azimuth angles, with A looking approximately upwind and $\mathrm{F}$ looking approximately crosswind.

\section{d. Radiance contrasts over the slicks, subsurface waves, and front}

On image pair 1 , surface slicks, most likely due to released oil, are detected on both sides of the Gulf Stream front at $30.05^{\circ} \mathrm{N}, 79.4^{\circ} \mathrm{W}$ and at $29.9^{\circ} \mathrm{N}, 80.35^{\circ} \mathrm{W}$ (red circles in Fig. 1). They all appear as dark spots on every image, that is, with a negative radiance contrast $B^{\prime} / B_{0} \simeq-0.15$. Those observations are shown with the colored dots on Fig. 3a, on the 2D plane of the equivalent monostatic look angles. In that figure, the center represents vertical (nadir) look, and pink circles are contours of equal zenith view angles $\theta_{m}$. The reference frame is rotated along the wind direction, supposed to blow from the NNW $\left(\varphi_{w}=-30^{\circ}\right)$. Nearby those slicks, the Gulf Stream inner front (red transect in Fig. 1, detailed in Fig. 1e) appears with different radiance contrasts $B^{\prime} / B_{0}$ of +0.10 and -0.20 for MERIS and MODIS Terra, respectively (Fig. 3b).

On image pair 2, a train of subsurface waves is detected (blue transect in Fig. 2, detailed in Fig. 2f). The crests and troughs appear in phase on MISR A and F, with an average radiance contrast in the troughs 

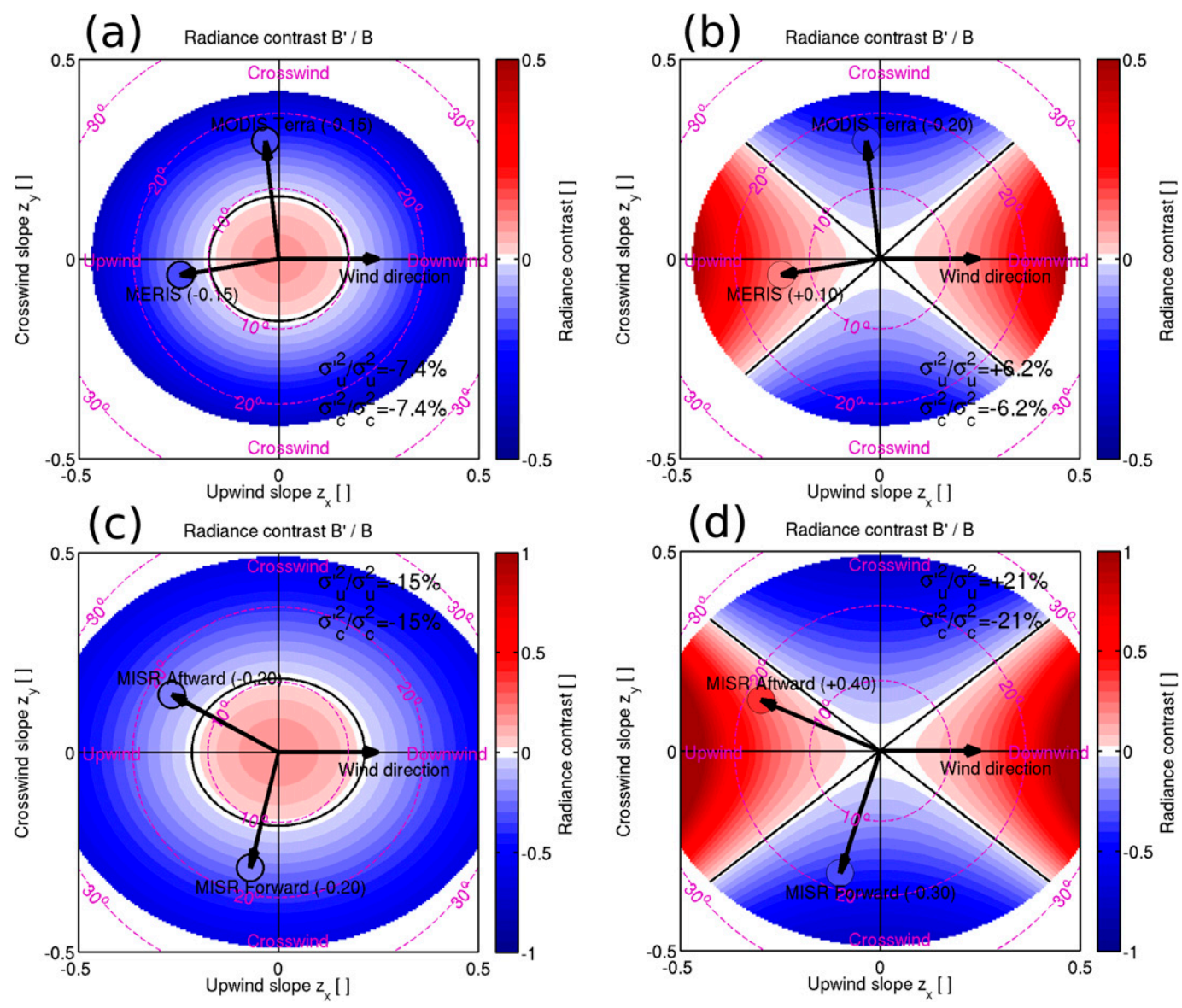

FIG. 3. Synthetic view of the radiance contrasts $B^{\prime} / B_{0}$ observed (colored dots) and idealized (colored contours) over (a) the slicks and (b) the Gulf Stream front of image pair 1, (c) the subsurface waves, and (d) the Gulf Stream front of image pair 2 . The axes represent the equivalent monostatic look angle, where nadir look is at the center and pink circles are contours of equal zenith angles $\theta_{m}$. The reference frame is rotated along the wind direction. For the idealized calculations, the background slope PDF $P$ is supposed Gaussian, following the values of Cox and Munk (1954) for a wind speed of 5 and $8 \mathrm{~m} \mathrm{~s}^{-1}$ for image pairs 1 and 2, respectively. Contours in (a) and (c) are the PDF contrasts $P^{\prime} / P$ calculated from an isotropic mss contrast (i.e., $\sigma_{u}^{2^{\prime}} / \sigma_{u}^{2}=\sigma_{c}^{2^{\prime}} / \sigma_{c}^{2}$ ) of $-7.4 \%$ and $-15 \%$, respectively. Contours in (b) and (c) are the PDF contrasts with an antisymmetric mss contrast (i.e., $\sigma_{u}^{2^{\prime}} / \sigma_{u}^{2}=-\sigma_{c}^{2^{\prime}} / \sigma_{c}^{2}$ ) of $6.2 \%$ and $21 \%$, respectively. As a noise limit of sun-glitter radiance, contours are not shown for $P<0.01$.

about -0.20 . Nearby, the Gulf Stream inner front (red transect in Fig. 2, detailed in Fig. 2e) appears with different radiance contrasts $B^{\prime} / B_{0}$ of +0.40 and -0.30 for MISR A and F, respectively. Those observations are shown as function of the equivalent monostatic look angles in Figs. $3 \mathrm{c}$ and $3 \mathrm{~d}$, where the wind is supposed to blow from the northwest $\left(\varphi_{w}=-50^{\circ}\right)$.

\section{e. Isotropic mss contrasts}

At scales $L<25 \mathrm{~km}$, the geometry can be considered constant and from (1) one has $B^{\prime} / B_{0}=P^{\prime} / P$, that is, local radiance contrasts are due to changes in the slope PDF. Assuming that the PDF is approximately 2D Gaussian, with the major axes in the upwind and crosswind directions, the PDF is written

$$
P\left(z_{x}, z_{y}\right)=\frac{1}{2 \pi \sigma_{u} \sigma_{c}} \exp -\left(\frac{z_{x}^{2}}{2 \sigma_{u}^{2}}+\frac{z_{y}^{2}}{2 \sigma_{c}^{2}}\right),
$$

where the upwind and crosswind mss are $\sigma_{u}^{2}$ and $\sigma_{c}^{2}$, respectively.

The PDF variations $P^{\prime}$ are related to mss variations $\left(\sigma_{u}^{2^{\prime}}, \sigma_{c}^{2^{\prime}}\right)$. In the presence of surface slicks, the ratio $\sigma_{c}^{2} / \sigma_{u}^{2}$ is conserved (Cox and Munk 1954; Kudryavtsev et al. 2012b), which means that the mss contrasts are isotropic:

$$
\frac{\sigma_{u}^{2^{\prime}}}{\sigma_{u}^{2}}=\frac{\sigma_{c}^{2^{\prime}}}{\sigma_{c}^{2}} .
$$

In such a case, the PDF contrast can be linearized for small mss contrast as 


$$
\frac{P^{\prime}}{P}=\frac{\sigma_{u}^{2^{\prime}}}{\sigma_{u}^{2}}\left(-1+\frac{z_{x}^{2}}{2 \sigma_{u}^{2}}+\frac{z_{y}^{2}}{2 \sigma_{c}^{2}}\right),
$$

where an ellipse separates the area around the center, the so-called inverted zone (where the PDF contrast has opposite sign to that of the mss contrast), from the rest of the slope plane. This is illustrated by the colored contours in Figs. 3a and 3c, where $P$ is defined by (4) with $\sigma_{u}^{2}=3.16 \times 10^{-3} U_{10}$ and $\sigma_{c}^{2}=3 \times 10^{-3}+1.92 \times 10^{-3} U_{10}$, the values of Cox and Munk (1954) for a wind speed $U_{10}$. The wind speed is set to 5 and $8 \mathrm{~m} \mathrm{~s}^{-1}$ for image pairs 1 and 2, respectively. The PDF contrasts $P^{\prime} / P$ are calculated from an isotropic mss contrast (i.e., $\left.\sigma_{u}^{2^{\prime}} / \sigma_{u}^{2}=\sigma_{c}^{2^{\prime}} / \sigma_{c}^{2}\right)$ of $-7.4 \%$ and $-15 \%$ for image pairs 1 and 2, respectively. Those values of the mss contrasts provide the best fit (in the least squares sense) to observed radiance contrasts.

The inversion occurs at angles $\theta_{m}=\arctan \left(\sqrt{2} \sigma_{u}\right)$ and $\theta_{m}=\arctan \left(\sqrt{2} \sigma_{c}\right)$ in the upwind and crosswind directions, respectively. According to Cox and Munk (1954), those angles are around $9^{\circ}-10^{\circ}$ and $10^{\circ}-12^{\circ}$ for wind speeds of 5 and $8 \mathrm{~m} \mathrm{~s}^{-1}$, respectively (see black ellipses on Figs. 3a and 3c).

Therefore, the four observed oceanic features of Fig. 3 are outside the inverted region (i.e., the colored dots are outside the black ellipses). This is well confirmed by the signatures of surface slicks of image pair 1 (Fig. 3a). Spots appear dark, whereas they would otherwise appear bright if they were inside the inverted region (e.g., Matthews 2005; Kudryavtsev et al. 2012b).

We note that (6) is valid for small mss contrasts only. In the case of large mss change, the location of the inversion can depart from the ellipse (see, e.g., Jackson and alpers 2010). In the present observations, the mss contrasts can reach up to $25 \%$. Therefore, (6) is not strictly valid. To remain consistent, all the contours of Fig. 3 are calculated using exact finite differences $\left(P_{2}-\right.$ $\left.P_{1}\right) / P$ instead of the linearization of $P^{\prime} / P$ given by (6).

\section{f. Anisotropic mss contrasts}

The Gulf Stream front appears on image pair 1 with a contrast inversion between MERIS $(+0.10)$ and MODIS Terra $(-0.20)$. Assuming that MERIS at $\theta_{m} \simeq$ $14^{\circ}$ is inside the inverted region (i.e., inside the ellipse), whereas assuming that MODIS Terra at $\theta_{m} \simeq 16.5^{\circ}$ is outside requires a wind speed of more than $10 \mathrm{~m} \mathrm{~s}^{-1}$, which is far above the light wind estimation on that day. Furthermore, in such case, the surface slicks west of the front would be inside the inverted region and would therefore appear bright on Fig. 1d, which is not the case. The contrast inversion of the front on image pair 1 thus cannot be explained by an isotropic mss variation.
There is also a contrast inversion of the Gulf Stream front on image pair 2 between MISR A $(+0.40)$ and MISR F (-0.30). Again, assuming that MISR A at $\theta_{m} \simeq$ $18^{\circ}$ upwind is inside the inverted region, whereas assuming that MISR $\mathrm{F}$ at $\theta_{m} \simeq 18^{\circ}$ crosswind is outside requires a wind speed of more than $18 \mathrm{~m} \mathrm{~s}^{-1}$. Again, it is much higher than the observations. Furthermore, in such a case, the subsurface waves (Fig. 2f) would appear with a sign reversal between the two images, which is not the case. The contrast inversion of the front on image pair 2 can neither be explained by an isotropic mss variation.

On the contrary, these observations indicate an anisotropic mss variation with an increase of the upwind mss and a decrease of the crosswind mss. This is illustrated in Figs. $3 b$ and $3 d$ where the mss is set to an increase in the upwind direction and a similar decrease in the crosswind direction. The values of the mss contrasts are set to $6.2 \%$ and $21 \%$ for image pairs 1 and 2 , respectively. Those provide the best fit to the observed radiance contrasts.

Such evidence of well-marked anisotropic mss modulation has never been reported before. It is the main result of this paper and has important consequences. This leads to consider that mss modulation induced by current can be a vectorial quantity (i.e., directional), with an upwind and a crosswind component, instead of a scalar quantity (i.e., omnidirectional) isotropically modulated (e.g., Dulov and Kudryavtsev 1990). This opens an observational methodology to retrieve current information from surface roughness analysis at multiple view angles.

\section{Surface roughness and current deformation types}

In this section, we investigate how the current gradient could have created such anisotropic mss modulations.

\section{a. Surface waves in currents}

In the presence of current, the conservation of wave action $N(\mathbf{x}, \mathbf{k}, t)$ reads (e.g., Phillips 1984)

$$
\frac{\partial N}{\partial t}+\left(c_{g i}+u_{i}\right) \frac{\partial N}{\partial x_{i}}=k_{j} \frac{\partial u_{j}}{\partial x_{i}} \frac{\partial N}{\partial k_{i}}+\frac{S}{\omega},
$$

where $\mathbf{c}_{g}$ is the group velocity, $\mathbf{u}$ is the current, $\mathbf{k}$ is the wavenumber, $\omega$ is the intrinsic frequency, and $S$ is the energy source that contains input from the wind, dissipation, and wave-wave nonlinear interactions. Repeated indices $i, j=1,2$ indicate summation over horizontal components. 
Following a relaxation approach (e.g., Keller and Wright 1975; Hughes 1978; Alpers and Hennings 1984), the action is written $N(\mathbf{x}, \mathbf{k}, t)=N_{0}(\mathbf{k})+N^{\prime}(\mathbf{x}, \mathbf{k}, t)$, where $N^{\prime}$ represents small disturbance with respect to a background value $N_{0}$ corresponding to the state undisturbed by currents. Sources rapidly restore toward equilibrium, which is represented by a linear relaxation $S / \omega=-N^{\prime} / \tau_{c}$, where the time scale $\tau_{c}(\mathbf{k})$ depends on the surface wave scales.

If the typical length scale $L$ of the current is larger than the relaxation length scale $l_{r}=\tau_{c} c_{g}$, the advection term on the left-hand side of (7) can be ignored. ${ }^{1}$ In a steady state, the action anomaly $N^{\prime}$ due to current variations then writes

$$
N^{\prime}(\mathbf{x}, \mathbf{k})=\tau_{c} k_{j} \frac{\partial u_{j}}{\partial x_{i}} \frac{\partial N_{0}}{\partial k_{i}} .
$$

The current deformation tensor $\partial u_{j} / \partial x_{i}$ can be separated in divergence $D$, vorticity $V$, strain $S_{t x}$ in the $x$ direction, and shear $S_{h x}$ in the $x$ direction:

$$
\begin{gathered}
D=\frac{\partial u}{\partial x}+\frac{\partial v}{\partial y}, \quad V=\frac{\partial v}{\partial x}-\frac{\partial u}{\partial y}, \\
S_{t x}=\frac{\partial u}{\partial x}-\frac{\partial v}{\partial y}, \quad S_{h x}=\frac{\partial v}{\partial x}+\frac{\partial u}{\partial y}, \quad \text { and } \\
{\left[\begin{array}{cc}
\frac{\partial u}{\partial x} & \frac{\partial u}{\partial y} \\
\frac{\partial v}{\partial x} & \frac{\partial v}{\partial y}
\end{array}\right]=\frac{1}{2}\left[\begin{array}{cc}
D+S_{t x} & -V+S_{h x} \\
V+S_{h x} & D-S_{t x}
\end{array}\right],}
\end{gathered}
$$

where notations $x, y$ and $u, v$ are used from now on in place of $x_{1}, x_{2}$ and $u_{1}, u_{2}$. Sketches of such current decomposition are shown in Fig. 4.

Using polar coordinates, the action anomaly can be rewritten

$$
\begin{aligned}
& N^{\prime}(\mathbf{x}, k, \phi)=\frac{\tau_{c} N_{0}}{2}\left\{D m_{k} \quad-V \quad m_{\phi}\right. \\
& +S_{t x}\left[\cos (2 \phi) m_{k} \quad-\sin (2 \phi) \quad m_{\phi}\right] \\
& \left.+S_{h x}\left[\sin (2 \phi) m_{k}+\cos (2 \phi) \quad m_{\phi}\right]\right\},
\end{aligned}
$$

\footnotetext{
${ }^{1}$ Under light to moderate winds, this is only strictly valid for short waves (typically $k>10 \mathrm{~m}^{-1}$ ). For intermediate-scale waves $\left(k \sim 1 \mathrm{~m}^{-1}\right)$, the advection term is not negligible (e.g., Phillips 1984; Lyzenga 1991). The equilibrium remains qualitatively unchanged but the action anomaly is reduced, spatially spread and shifted from the current gradient. For simplicity, we do not discuss this effect but the numerical calculations in section 4 do include advection.
}

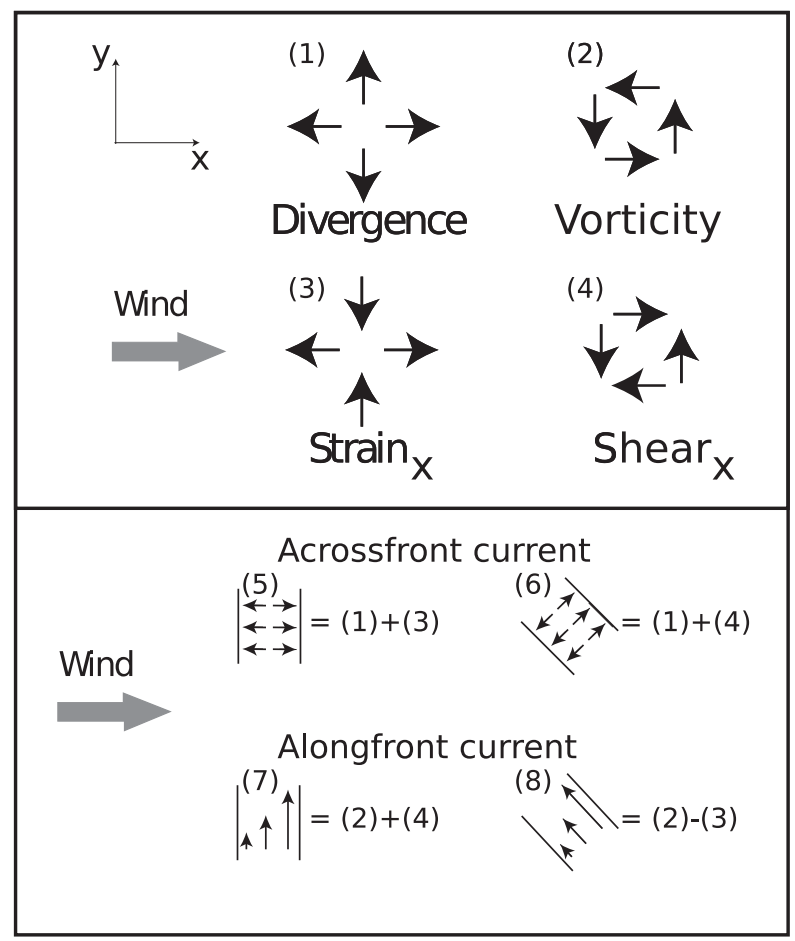

FIG. 4. (1-4) Sketch of the current gradient decomposition into divergence $D$, vorticity $V$, strain $S_{t x}$ in the $x$ direction, and shear $S_{h x}$ in the $x$ direction. (5-8) Simple one-dimensional current features such as along-front and across-front currents are shown with their decomposition on such deformation basis.

where $k$ and $\phi$ are the wavenumber magnitude and direction and where $m_{k}=\partial \ln N_{0} / \partial \ln k$ and $m_{\phi}=\partial \ln N_{0} / \partial \phi$.

\section{b. Changes of mean square slopes}

From the wave action anomaly $N^{\prime}$, the mss anomalies in the upwind and crosswind directions are

$$
\begin{aligned}
& \sigma_{u}^{2^{\prime}}(\mathbf{x})=\int_{k} \int_{\phi} \omega^{-1} k N^{\prime} k^{2} \cos ^{2} \phi d k k d \phi, \\
& \sigma_{c}^{2^{\prime}}(\mathbf{x})=\int_{k} \int_{\phi} \omega^{-1} k N^{\prime} k^{2} \sin ^{2} \phi d k k d \phi,
\end{aligned}
$$

where without loss of generality we have set in this section the $x$ axis in the wind direction.

\section{c. Wind wave spectral symmetry}

We now assume that the angular spread of the background wave spectrum is symmetrical about the wind direction, which is a good approximation for short wind waves (e.g., Donelan et al. 1985; Elfouhaily et al. 1997; Yurovskaya et al. 2013). Since we have set the $x$ axis in the wind direction, the wave spectrum $N_{0}(\mathbf{x}, k, \phi)$ is then an even function of $\phi$, and the same property is transferred to the relaxation time $\tau_{c}(k, \phi)$. Note that $m_{k} N_{0}$ is thus 
even, whereas $m_{\phi} N_{0}$ is odd. The integrals in (12) over the wave directions $\phi$ of any odd function will cancel out.

Substituting (11) into (12), the $V$ and $S_{h x}$ contributions cancel out because they are odd functions of $\phi$. Vorticity $V$ and shear in the wind direction $S_{h x}$ create no mss anomalies in the upwind or crosswind directions. The physical reason is that for those two types of currents, the mss anomaly due to modulation of waves propagating in the direction $\phi$ is exactly compensated by that of waves propagating in the direction $-\phi$.

Note that this result is valid with the wind along the $x$ direction. If the wind blows at an angle $\phi_{w}$ to the $x$ axis, the result holds with the strain and shear taken along the $\phi_{w}$ direction, calculated as

$$
\left[\begin{array}{c}
S_{t w} \\
S_{h w}
\end{array}\right]=\left[\begin{array}{cc}
\cos 2 \phi_{w} & -\sin 2 \phi_{w} \\
\sin 2 \phi_{w} & \cos 2 \phi_{w}
\end{array}\right]\left[\begin{array}{c}
S_{t x} \\
S_{h x}
\end{array}\right],
$$

and we remind that divergence and vorticity do not depend upon any reference direction.

\section{d. Divergence and strain}

Out of four types of current deformation, only two-divergence $D$ and strain in the wind direction $S_{t x}$-create mss anomalies in (12). The mss anomaly can be rewritten from (11) and (12) in the form

$$
\sigma_{u}^{2^{\prime}}=\left(D+\beta_{u} S_{t x}\right) \times a_{u},
$$

where the parameters $a_{u}$ and $\beta_{u}$ only depend on the properties of the wave field.

The amplitude parameter $a_{u}$ is defined as

$$
a_{u}=\int_{k} \int_{\phi} \omega^{-1} \tau_{c} k^{3} \frac{N_{0}}{2} m_{k} \cos ^{2} \phi d k k d \phi,
$$

and the polarization parameter $\beta_{u}$ is defined as

$$
\beta_{u}=\frac{\int_{k} \int_{\phi} \omega^{-1} \tau_{c} k^{3} N_{0}\left[\cos (2 \phi) m_{k}-\sin (2 \phi) m_{\phi}\right] \cos ^{2} \phi d k k d \phi}{\int_{k} \int_{\phi} \omega^{-1} \tau_{c} k^{3} N_{0} m_{k} \cos ^{2} \phi d k k d \phi} .
$$

The parameters $a_{c}$ and $\beta_{c}$ for the crosswind component of the mss are defined similarly by replacing $\cos ^{2} \phi$ by $\sin ^{2} \phi$ in the above.

We note that the amplitude parameters $a_{u}$ and $a_{c}$ are both negative because $m_{k}<0 .^{2}$ This means that divergence creates mss anomalies of similar sign, negative, in the upwind and crosswind directions. Physically, the reason is that waves traveling in any direction are elongated by the current divergence (see sketch Fig. 5a). Divergence thus creates quasi-isotropic mss modulations. This is illustrated in Fig. 5b where we plot the contrast $P^{\prime} / P$ of the slope PDF for a current divergence. Here, we set the wind to $5 \mathrm{~m} \mathrm{~s}^{-1}$, background wind waves are supposed fully developed, and divergence is set to $D=5 \times 10^{-5} \mathrm{~s}^{-1}$. The mss contrasts $\sigma_{u}^{2^{\prime}} / \sigma_{u}^{2}=-15 \%$ and $\sigma_{c}^{2^{\prime}} / \sigma_{c}^{2}=-11 \%$ are calculated using (14), (15), and (16), with the parameters $a_{u}, a_{c}, \beta_{u}$, and $\beta_{c}$ calculated using the model of Kudryavtsev et al. (2005). The contrast of slope PDF is then calculated using (4). As evidenced, divergence cannot create the anisotropic mss modulations observed over the Gulf Stream.

\footnotetext{
${ }^{2}$ This is valid for all waves except for waves longer than the spectral peak, which have a negligible impact on the mss modulation.
}

On the contrary for a current strain, the polarization parameters change signs $\beta_{c}<0<\beta_{u}$ [see Rascle et al. (2014, their section 3) for a discussion of these polarization parameters]. This means that a positive strain creates a positive (negative) mss anomaly in the upwind (crosswind) direction (Fig. 5c). The physical reason is that waves traveling in the wind direction are elongated by the current, whereas waves traveling in the crosswind direction are compressed (see sketch Fig. 5a). The model predicts mss contrasts of $\sigma_{u}^{2^{\prime}} / \sigma_{u}^{2}=-4 \%$ and $\sigma_{c}^{2^{2}} / \sigma_{c}^{2}=+9 \%$ for a strain in the wind direction of $S_{t x}=$ $5 \times 10^{-5} \mathrm{~s}^{-1}$. The resulting contrast of the slope PDF is clearly anisotropic (see Fig. 5c).

\section{Interpretation of the observations}

On image pairs 1 and 2, the wind was blowing approximately from the northwest. We make the hypothesis that the Gulf Stream Current is nondivergent and flowing northward along the temperature front, with current shear in the across-front direction. In the wind direction, this situation corresponds to a positive vorticity plus a negative strain (see sketch Fig. 6a; see also sketch 8 in Fig. 4). The expected mss contrast for such negative strain must then be positive (negative) in the upwind (crosswind) look direction, respectively. 


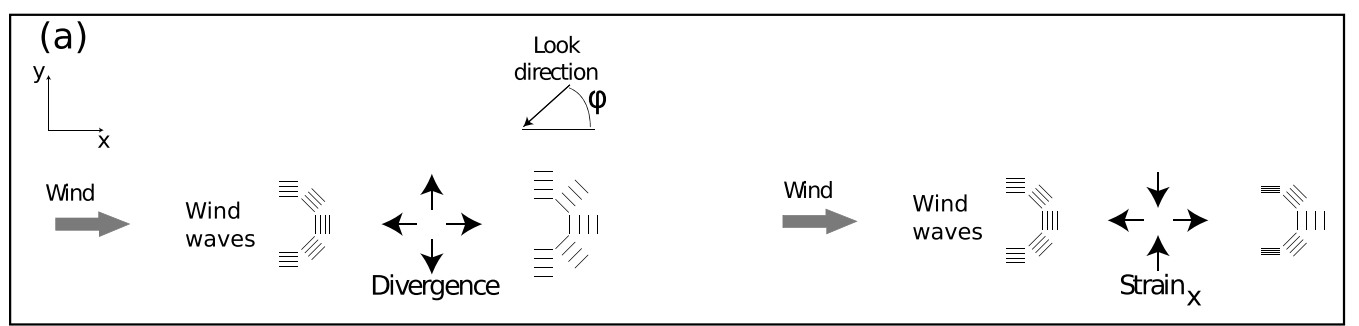

(b) Slope PDF contrast $P^{\prime} / P$ for Divergence

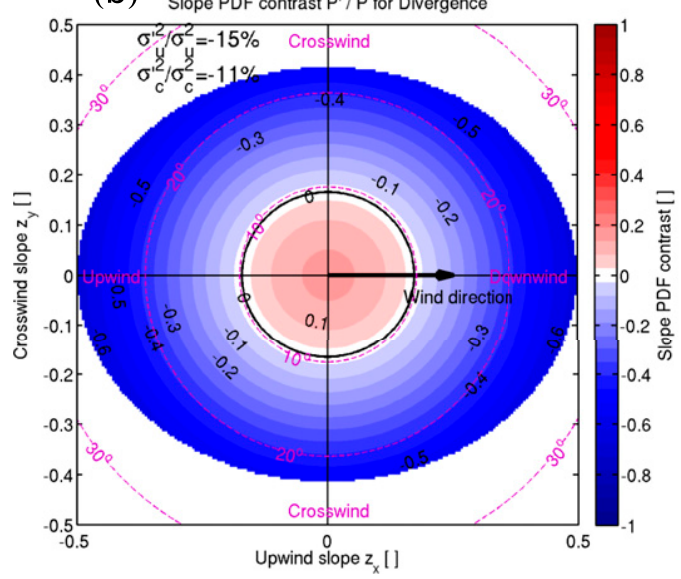

(C) Slope PDF contrast $\mathrm{P}^{\prime} / \mathrm{P}$ for $\operatorname{Strain}_{\mathrm{x}}$

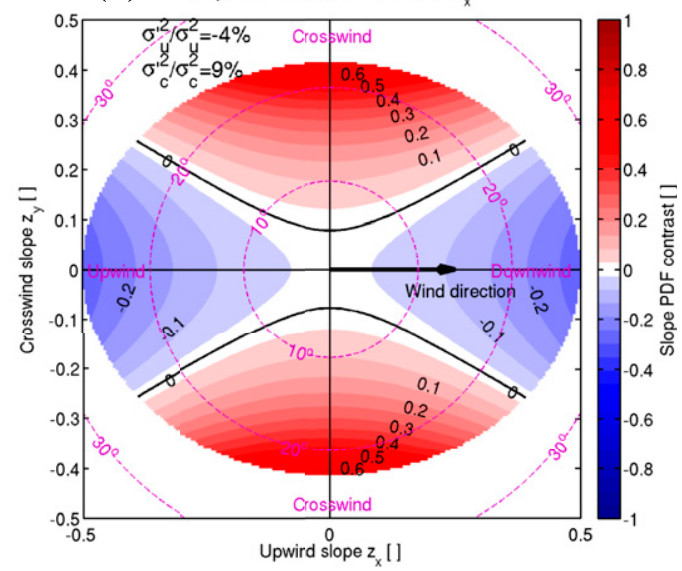

FIG. 5. (a) Sketch of a spectrum of wind waves propagating over a current divergence and over a current strain in the wind direction. In the case of divergence, all waves are elongated. In the case of strain, along-wind waves are elongated whereas crosswind waves are compressed. (b),(c) Contrasts of the slope PDF induced by current divergence $\left(D=5 \times 10^{-5} \mathrm{~s}^{-1}, S_{t}=0\right)$ or by current strain $\left(D=0, S_{t}=5 \times 10^{-5} \mathrm{~s}^{-1}\right)$, as function of the equivalent monostatic look angles. The mss contrasts $\sigma_{u}^{2^{\prime}} / \sigma_{u}^{2}$ and $\sigma_{c}^{2^{\prime}} / \sigma_{c}^{2}$ are calculated using (14), (15), and (16), with the parameters $a_{u}, a_{c}, \beta_{u}$, and $\beta_{c}$ calculated using the model of Kudryavtsev et al. (2005) for a wind speed of $5 \mathrm{~m} \mathrm{~s}^{-1}$ and fully developed background wind waves. The PDF contrasts are then calculated using (4).

This is in agreement with the observed radiance contrasts in image pairs 1 and 2; MERIS and MISR A look upwind and have positive contrasts, and MODIS Terra and MISR F look crosswind and have negative contrasts.

To further strengthen the interpretation, we run the model of Kudryavtsev et al. (2005) over the current configuration depicted in Fig. 6a. The along-front current is specified as

$$
v=v_{0} \frac{1+\tanh (x / L)}{2},
$$

with $x$ as the across-front coordinate: $v_{0}=-0.3 \mathrm{~m} \mathrm{~s}^{-1}$ and $L=300 \mathrm{~m}$. The wind is set to $5 \mathrm{~m} \mathrm{~s}^{-1}$ at a slanting (a)

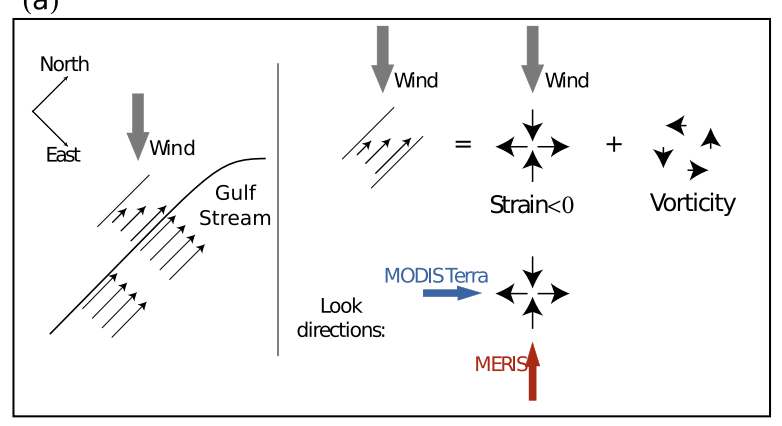

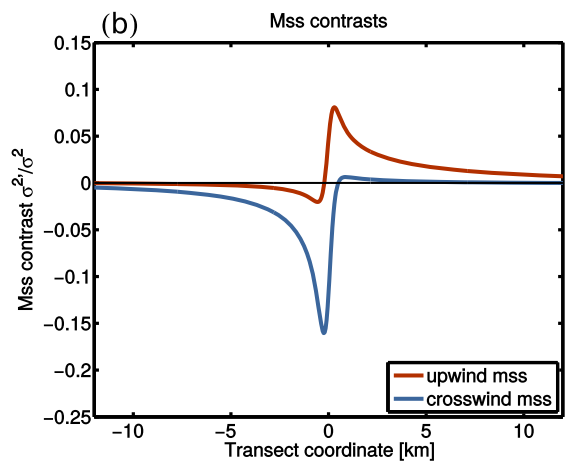

FIG. 6. (left) Sketch of the Gulf Stream idealized simplification. (right) Modeled upwind and crosswind mss contrasts corresponding to such wind/current configuration. We used the model of Kudryavtsev et al. (2005); see text for details on the wind, waves, and current inputs to the model. 
angle $\left(45^{\circ}\right)$. The background wind waves are supposed fully developed. The current thus has a negative strain in the wind direction of $-5 \times 10^{-4} \mathrm{~s}^{-1}$ over approximately $1000 \mathrm{~m}$. For each component of the wave spectrum, the model essentially solves the conservation of wave action [(7)] written in a relaxation approximation. An additional term of short-wave generation by longer breaking waves is included in the model but does not qualitatively alter the mss calculations [see Kudryavtsev et al. $(2005,2014)$ for more details]. The resulting upwind and crosswind mss contrasts are shown in Fig. $6 \mathrm{~b}$ and are in good qualitative agreement with the observed radiance contrasts. The upwind mss has a positive contrast, while the crosswind mss has a negative contrast. Note that here the propagation by the group velocity $\left[c_{g}\right.$ in the lhs of (7)] is included in the conservation of wave action. This reduces the amplitude of the mss contrast. This also induces a slight downwind phase shift of the upwind contrast, which is visible in the observations of image pair 1 .

Note that the current gradient values in (17) are arbitrarily chosen. A quantitative estimation of the current gradient from the surface roughness observation would require a more complete description of the propagation effects and is left for further modeling and observational works.

\section{Discussion}

The present observations clearly indicate anisotropic mss anomalies. As those cannot be associated with surfactants, they are most likely induced by anisotropic current deformation. Divergence is isotropic and thus creates quasi-isotropic mss anomalies. On the contrary, strain in the wind direction can create anisotropic mss anomalies. This is confirmed by a wave model in a relaxation approximation and under the hypothesis of a wave spectrum symmetrical about the wind direction. Away from those approximations, for instance with the inclusion of finite-amplitude effects (e.g., Phillips 1984), other deformations like vorticity and shear might also create mss anisotropic modulations, although certainly an order of magnitude smaller. In addition, higher-order wave slope statistics like skewness and peakedness (e.g., Chapron et al. 2000; Bréon and Henriot 2006) might also be considered to better interpret radiance contrasts. In this case, the Gaussian approximation of slope PDF should be relaxed. Yet, to leading order, the mss changes likely dominate the PDF variations.

The expected strong mss anisotropy induced by strain can open new opportunities to separate strain from divergence, provided roughness observations at multiple azimuth angles are available (see Fig. 5b). Almost isotropic, divergence signatures will appear for all viewing geometries. In support of studies of ocean surface dynamics, a methodology can thus be efficiently refined to detect divergence areas, directly related to subsurface vertical velocities.

According to these developments, it is important to better describe the angular spreading of short wind waves as well as the impact of longer breaking waves on the short-scale roughness anisotropy, in particular under vigorous wave breaking occurrence. These are the key mechanisms at play for the roughness modulation by strain (see Rascle et al. 2014, their Figs. 3 and 4). Observations of wave breaking statistics within current gradients will then be crucial to improving our understanding of those mechanisms.

Finally, it should be mentioned that a modification of the atmospheric boundary layer over the Gulf Stream front can create a change of wind, in turn creating mss anomalies. More precisely, a change of wind speed is likely to create quasi-isotropic mss anomalies, while a change of wind direction is likely to create anisotropic mss anomalies. Those effects seemingly occur at larger spatial scales than current refraction, as found using simplified atmospheric models (Kudryavtsev et al. 2005, their section 4). In situ observations are not conclusive (e.g., Beal et al. 1997) and lack rapid spatial coverage. Future observations and modeling of ocean-atmosphere interactions at high $(100 \mathrm{~m})$ spatial resolution, all together coupled with waves, will certainly clarify that matter.

\section{Conclusions}

In the present paper, we analyze the surface roughness modulations induced by the small-scale current gradient at the inner front of the Gulf Stream. We do not consider microwave radar roughness but instead focus on optical roughness. We use a set of two pairs of quasi-simultaneous optical observations at different look angles within the sun glitter. Surface roughness modulations are interpreted in terms of changes in directional properties of wave mean square slope (mss).

First, we show evidence that the mss modulations induced by the surface current are not scalar (i.e., omnidirectional or isotropic) quantities but vectorial (i.e., directional) quantities, with an upwind and a crosswind component. These possible anisotropic modulations emphasize the need for observations at multiple look angles, in particular at multiple azimuth look angles, to retrieve the two components of the mss anomalies.

Second, anisotropic modulations cannot be explained by the presence of surfactants nor by the divergence of 
(a)

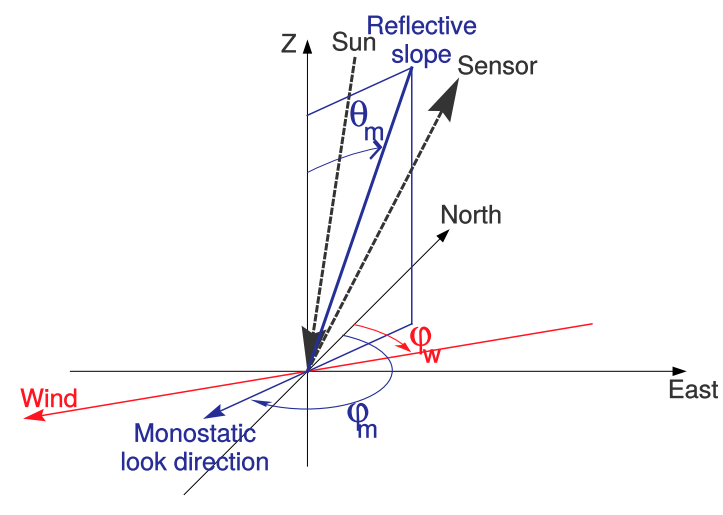

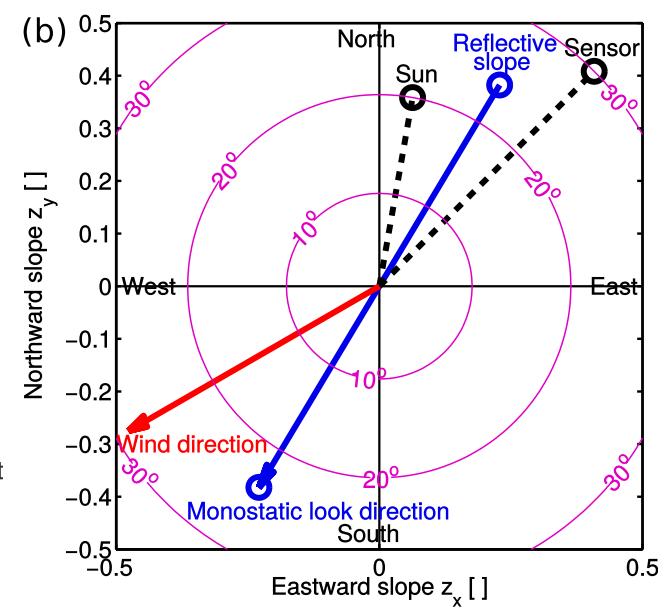

FIG. A1. (a) Sketch of the bistatic geometry of sun-glitter observations. (b) Corresponding eastward and northward slopes. See text for more details.

the current. We explain those anisotropic mss anomalies by the current strain in the wind direction. The use of surface roughness observations at multiple look angles can thus provide a very efficient method to retrieve two components of the current gradient: the divergence and the strain in the wind direction.

Future investigations could certainly capitalize on the proposed decomposition method to further advance the combined use of passive optical and active radar microwave observations. Evaluation of different combinations of high-resolution polarized radar signals can help to distinguish isotropic wave breaking signatures (Kudryavtsev et al. 2013, 2014). This may further help to refine the framework for using different remote sensing observations to advance the understanding and monitoring of the upper-ocean dynamics.

Acknowledgments. We acknowledge the financial support of the ANR (French Agence Nationale pour la Recherche) through the REDHOTS project; of the ESA (European Space Agency) through the STSE MESO3D, GlobCurrent, and SARONG projects; and of the LabexMer (French Laboratoire d'Excellence) Axe1. We also acknowledge V. Kudryavtsev, RSHU, SPb, for fruitful discussions and help implementing the numerical forward simulation and F. Collard, OceanDataLab, for motivating the analysis and interpretation of numerous observations. We thank Steven Delwart at ESAESRIN for providing the Level-1 MERIS data (and we used the website http://lance-modis.eosdis.nasa.gov to download the Level-1 MODIS data). We thank Emmanuelle Autret for computing the brightness temperature data and A. Bentamy for providing scatterometer observations.

\section{APPENDIX}

\section{Observation Geometry: Bistatic Configuration and Equivalent Monostatic Angles}

Figure A1a sketches the bistatic geometry of the sunglitter observations. The surface slope needs to be tilted at a certain angle to specularly reflect the sun light toward the radiometer. The normal to this surface slope defines the angle at which an equivalent monostatic system (e.g., radar) would look at the scene. The equivalent monostatic look has a zenith angle $\theta_{m}$ and an azimuth angle $\varphi_{m}$. Note that we use the convention for the azimuth that the look direction is away from the equivalent monostatic system. Figure A1b shows the corresponding eastward and northward slopes (nadir is at the center; pink contours are contours of equal zenith angles). In this example, the wind direction is $\varphi_{w}=60^{\circ}$ (east-north-east), the sun is at $\theta_{\mathrm{su}}=20^{\circ}$ and $\varphi_{\mathrm{su}}=10^{\circ}$, and the sensor is at $\theta_{\mathrm{se}}=30^{\circ}$ and $\varphi_{\mathrm{se}}=45^{\circ}$, leading to equivalent monostatic look angles $\theta_{m}=24^{\circ}$ and $\varphi_{m}=$ $211^{\circ}$ (i.e., approximately looking downwind.)

\section{REFERENCES}

Alpers, W., 1985: Theory of radar imaging of internal waves. $\mathrm{Na}$ ture, 314, 245-247, doi:10.1038/314245a0.

_ of underwater bottom topography by real and synthetic aperture radar. J. Geophys. Res., 8, 10 529-10 546, doi:10.1029/ JC089iC06p10529.

Apel, J. R., H. M. Byrne, J. R. Proni, and R. L. Charnell, 1975: Observations of oceanic internal and surface waves from the Earth Resources Technology Satellite. J. Geophys. Res., 80, 865-881, doi:10.1029/JC080i006p00865.

Beal, R. C., P. S. DeLeonibus, and I. Katz, 1981: Spaceborne Synthetic Aperture Radar for Oceanography. Vol. 7. Johns Hopkins University Press, 215 pp. 
— , V. Kudryavtsev, D. Thompson, S. Grodsky, D. Tilley, V. Dulov, and H. Graber, 1997: The influence of the marine atmospheric boundary layer on ERS 1 synthetic aperture radar imagery of the Gulf Stream. J. Geophys. Res., 102, 57995814, doi:10.1029/96JC03109.

Brannigan, L., D. P. Marshall, A. Naveira-Garabato, and A. G. Nurser, 2015: The seasonal cycle of submesoscale flows. Ocean Modell., 92, 69-84, doi:10.1016/j.ocemod.2015.05.002.

Bréon, F., and N. Henriot, 2006: Spaceborne observations of ocean glint reflectance and modeling of wave slope distributions. J. Geophys. Res., 111, C06005, doi:10.1029/2005JC003343.

Callies, J., R. Ferrari, J. M. Klymak, and J. Gula, 2015: Seasonality in submesoscale turbulence. Nat. Commun., 6, 6862, doi:10.1038/ ncomms7862.

Chapron, B., V. Kerbaol, D. Vandemark, and T. Elfouhaily, 2000: Importance of peakedness in sea surface slope measurements. J. Geophys. Res., 105, 17 195-17 202, doi:10.1029/2000JC900079.

Cox, C., and W. Munk, 1954: Measurement of the roughness of the sea surface from photographs of the sun's glitter. J. Opt. Soc. Amer., 44, 838-850, doi:10.1364/JOSA.44.000838.

Dee, D., and Coauthors, 2011: The ERA-Interim reanalysis: Configuration and performance of the data assimilation system. Quart. J. Roy. Meteor. Soc., 137, 553-597, doi:10.1002/ qj. 828 .

Diner, D. J., and Coauthors, 1989: MISR: A multiangle imaging spectroradiometer for geophysical and climatological research from Eos. IEEE Trans. Geosci. Remote Sens., 27, 200-214, doi:10.1109/36.20299.

Donelan, M. A., J. Hamilton, and W. H. Hui, 1985: Directional spectra of wind-generated waves. Philos. Trans. Roy. Soc. London, A315, 509-562, doi:10.1098/rsta.1985.0054.

Dulov, V. A., and V. N. Kudryavtsev, 1990: Imagery of the inhomogeneities of currents on the ocean surface state. Sov. J. Phys. Oceanogr., 1, 325-336, doi:10.1007/BF02196830.

Elfouhaily, T., B. Chapron, K. Katsaros, and D. Vandemark, 1997: A unified directional spectrum for long and short wind-driven waves. J. Geophys. Res., 102, 15781-15796, doi:10.1029/ 97JC00467.

Espedal, H. A., O. M. Johannessen, J. A. Johannessen, E. Dano, D. Lyzenga, and J. Knulst, 1998: COASTWATCH'95: ERS 1/2 SAR detection of natural film on the ocean surface. J. Geophys. Res., 103, 24 969-24 982, doi:10.1029/98JC01660.

Ferrari, R., 2011: A frontal challenge for climate models. Science, 332, 316-317, doi:10.1126/science.1203632.

Fu, G., K. Baith, and C. McClain, 1998: SEADAS: The SeaWiFS data analysis system. Proc. Fourth Pacific Ocean Remote Sensing Conf., Qingdao, China, PORSEC Association, 73-79.

Fu, L.-L., and B. Holt, 1983: Some examples of detection of oceanic mesoscale eddies by the SEASAT synthetic-aperture radar. J. Geophys. Res., 88, 1844-1852, doi:10.1029/JC088iC03p01844.

Hughes, B., 1978: The effect of internal waves on surface wind waves 2 . Theoretical analysis. J. Geophys. Res., 83, 455-465, doi:10.1029/JC083iC01p00455.

Huot, J., M. Rast, S. Delwart, J. Bezy, G. Levrini, and H. Tait, 2001: The optical imaging instruments and their applications: AATSR and MERIS. ESA Bull., 106, 56-66.

Jackson, C. R., and W. Alpers, 2010: The role of the critical angle in brightness reversals on sunglint images of the sea surface. J. Geophys. Res. Oceans, 115, C09019, doi:10.1029/ 2009JC006037.

Keller, W., and J. Wright, 1975: Microwave scattering and the straining of wind-generated waves. Radio Sci., 10, 139-147, doi:10.1029/RS010i002p00139.
Klein, P., and G. Lapeyre, 2009: The oceanic vertical pump induced by mesoscale and submesoscale turbulence. Annu. Rev. Mar. Sci., 1, 351-375, doi:10.1146/annurev.marine.010908.163704.

Kudryavtsev, V., D. Akimov, J. Johannessen, and B. Chapron, 2005: On radar imaging of current features: 1 . Model and comparison with observations. J. Geophys. Res., 110, C07016, doi:10.1029/2004JC002505.

- A. Myasoedov, B. Chapron, J. A. Johannessen, and F. Collard, 2012a: Imaging mesoscale upper ocean dynamics using synthetic aperture radar and optical data. J. Geophys. Res., 117, C04029, doi:10.1029/2011JC007492.

$\longrightarrow, \ldots, \ldots, \ldots$, and $\_, 2012$ b: Joint sun-glitter and radar imagery of surface slicks. Remote Sens. Environ., 120, 123-132, doi:10.1016/j.rse.2011.06.029.

Kudryavtsev, V. N., B. Chapron, A. G. Myasoedov, F. Collard, and J. A. Johannessen, 2013: On dual co-polarized SAR measurements of the ocean surface. IEEE Geosci. Remote Sens. Lett., 10, 761-765, doi:10.1109/LGRS.2012.2222341.

_- I. Kozlov, B. Chapron, and J. Johannessen, 2014: Quadpolarization SAR features of ocean currents. J. Geophys. Res. Oceans, 119, 6046-6065, doi:10.1002/2014JC010173.

Lévy, M., R. Ferrari, P. J. S. Franks, A. P. Martin, and P. Rivière, 2012: Bringing physics to life at the submesoscale. Geophys. Res. Lett., 39, L14602, doi:10.1029/2012GL052756.

Lyzenga, D. R., 1991: Interaction of short surface and electromagnetic waves with ocean fronts. J. Geophys. Res., 96, 10 765-10 772, doi:10.1029/91JC00900.

Matthews, J., 2005: Stereo observation of lakes and coastal zones using ASTER imagery. Remote Sens. Environ., 99, 16-30, doi:10.1016/j.rse.2005.04.029.

McWilliams, J., F. Colas, and M. Molemaker, 2009: Cold filamentary intensification and oceanic surface convergence lines. Geophys. Res. Lett., 36, L18602, doi:10.1029/ 2009GL039402.

Nagai, T., A. Tandon, and D. Rudnick, 2006: Two-dimensional ageostrophic secondary circulation at ocean fronts due to vertical mixing and large-scale deformation. J. Geophys. Res., 111, C09038, doi:10.1029/2005JC002964.

OSI SAF, 2016: ASCAT wind product user manual. Tech. Rep. SAF/OSI/CDOP/KNMI/TEC/MA/126, 23 pp. [Available online at http://projects.knmi.nl/scatterometer/publications/pdf/ ASCAT_Product_Manual.pdf.]

Özgökmen, T. M., and Coauthors, 2014: Research overview of the Consortium for Advanced Research on Transport of Hydrocarbon in the Environment (CARTHE). Int. Oil Spill Conf. Proc., Vol. 2014, Savannah, GA, American Petroleum Institute, 544-560.

Perruche, C., P. Rivière, G. Lapeyre, X. Carton, and P. Pondaven, 2011: Effects of surface quasi-geostrophic turbulence on phytoplankton competition and coexistence. J. Mar. Res., 69 , 105-135, doi:10.1357/002224011798147606.

Phillips, O. M., 1984: On the response of short ocean wave components at a fixed wavenumber to ocean current variations. J. Phys. Oceanogr., 14, 1425-1433, doi:10.1175/1520-0485(1984)014<1425: OTROSO $>2.0 . \mathrm{CO} ; 2$.

Rascle, N., B. Chapron, A. Ponte, F. Ardhuin, and P. Klein, 2014: Surface roughness imaging of currents shows divergence and strain in the wind direction. J. Phys. Oceanogr., 44, 2153-2163, doi:10.1175/JPO-D-13-0278.1.

Salomonson, V. V., W. Barnes, P. W. Maymon, H. E. Montgomery, and H. Ostrow, 1989: MODIS: Advanced facility instrument for studies of the Earth as a system. IEEE Trans. Geosci. Remote Sens., 27, 145-153, doi:10.1109/36.20292. 
Shcherbina, A. Y., and Coauthors, 2015: The LatMix summer campaign: Submesoscale stirring in the upper ocean. Bull. Amer. Meteor. Soc., 96, 1257-1279, doi:10.1175/ BAMS-D-14-00015.1.

Spall, M. A., 1995: Frontogenesis, subduction, and cross-front exchange at upper ocean fronts. J. Geophys. Res., 100, 2543 2557, doi:10.1029/94JC02860.

Thomas, L. N., A. Tandon, and A. Mahadevan, 2008: Submesoscale processes and dynamics. Ocean Modeling in an Eddying Regime, Geophys. Monogr., Vol. 177, Amer. Geophys. Union, 17-38, doi:10.1029/177GM04.
Vandemark, D., P. Mourad, S. Bailey, T. Crawford, C. Vogel, J. Sun, and B. Chapron, 2001: Measured changes in ocean surface roughness due to atmospheric boundary layer rolls. J. Geophys. Res., 106, 4639-4654, doi:10.1029/1999JC000051. Yurovskaya, M., V. Dulov, B. Chapron, and V. Kudryavtsev, 2013: Directional short wind wave spectra derived from the sea surface photography. J. Geophys. Res. Oceans, 118, 43804394, doi:10.1002/jgrc.20296.

Zhong, Y., and A. Bracco, 2013: Submesoscale impacts on horizontal and vertical transport in the Gulf of Mexico. J. Geophys. Res. Oceans, 118, 5651-5668, doi:10.1002/jgrc.20402. 